\title{
Applicability of Lung Equivalent Phantom Using the Cork with Absorbed Water in Radiotherapeutic Dosimetry
}

\author{
Hiraku Fuse1, ${ }^{1}$ Tatsuya Fujisaki1, Ryutaro Ikeda², Zen Hakani ${ }^{3}$ \\ ${ }^{1}$ Department of Radiological Sciences, Ibaraki Prefectural University of Health Sciences, Ibaraki, Japan \\ ${ }^{2}$ Division of Medical Physics, Department of Radiation Oncology, Tohoku University Graduate School of Medicine, \\ Sendai, Japan \\ ${ }^{3}$ Department of Radiological Technology, JA Toride Medical Center, Ibaraki, Japan \\ Email: fuseh@ipu.ac.jp
}

How to cite this paper: Fuse, H., Fujisaki, T., Ikeda, R. and Hakani, Z. (2018) Applicability of Lung Equivalent Phantom Using the Cork with Absorbed Water in Radiotherapeutic Dosimetry. International Journal of Medical Physics, Clinical Engineering and Radiation Oncology, 7, 27-34.

https://doi.org/10.4236/ijmpcero.2018.71003

Received: December 20, 2017

Accepted: February 4, 2018

Published: February 7, 2018

Copyright (C) 2018 by authors and Scientific Research Publishing Inc. This work is licensed under the Creative Commons Attribution International License (CC BY 4.0).

http://creativecommons.org/licenses/by/4.0/

\begin{abstract}
The radiation dosimetry in medical practice requires special phantom to simulate the organs and tissues of a human body. To achieve the same elemental composition as that of the human lung by weight percent, we constructed lung equivalent phantom (LEP) using cork with absorbed water in order for it to uniformly absorb the water. Then, we presented the physical properties and dosimetric characteristics of other commercial phantoms and the LEP. We found that the physical properties and dosimetric characteristics of the LEP were approximately the same as those of human lung tissue. LEP constitutes a new dosimetry tool because it can provide the dose distributions and point doses similar to those for the body with respiratory motion of lung.
\end{abstract}

\section{Keywords}

Cork, Lung Equivalent Phantom, Respiratory Motion, Dosimetry

\section{Introduction}

The application of radiotherapy in medical practice as dosimetry requires special phantom to simulate the organs and tissues of a human body. This phantom includes some dosimetry phantoms and test objects, and use commissioning of treatment planning system and dose distribution verification processes [1] [2] [3]. With regard to elemental composition, some commercial lung phantoms consist of 60 to approximately $75 \mathrm{wt} . \%$ carbon, approximately $10 \mathrm{wt} . \%$ hydrogen and approximately $20 \mathrm{wt} . \%$ oxygen [4]. In contrast, healthy adult lung (ICRU44) tissue consists of approximately $10 \mathrm{wt} . \%$ carbon, approximately $10 \mathrm{wt} . \%$ hydro- 
gen and approximately $75 \mathrm{wt} . \%$ oxygen [5]. The physical properties of commercial lung phantoms are expected to differ from those of human lung tissue. Elemental composition is an important parameter for determining cross-sections for dosimetry calculations. Some researchers have used cork with a density of approximately $0.2-0.4 \mathrm{~g} / \mathrm{cm}^{3}$ to represent normal lung tissue [6]. Cork consists of $45 \%$ suberin, $27 \%$ lignin, $12 \%$ polysaccharides, $10 \%$ extractives and $5 \%$ ash; hence, its elemental composition is approximately $60 \mathrm{wt} \%$ carbon, approximately $8 \mathrm{wt} . \%$ hydrogen and approximately $35 \mathrm{wt} . \%$ oxygen [7] [8]. The percentage of the carbon content in cork is markedly different from that in the lung (ICRU44) tissue. Chang et al. [4] concluded that the physical properties and dosimetric characteristics of the elemental composition of cork are very similar to those of the lung (ICRU44) tissue. However, the cork samples they used varied in their cross-sections because of varying elemental compositions. Furthermore, Aarup et al. have found that, when a density change occurs, the difference in the dose to the target between the Monte Carlo (MC) and TPS algorithm depends systematically on the density of the surrounding lung [9]. On other hands, Gafchromic film (International Specialty Products, Wayne, NJ) are widely used in radiotherapy fields. Paelinck et al. [10] were concluded that Gafchromic film measurements are reliable methods to establish the dose in and around lung tissue. Gafchromicfilm have good accuracy in inhomogeneity region dosimetry. The present study aims to develop a lung equivalent phantom (LEP) by soaking cork in plain water so that it absorbs water uniformly. We presented the physical properties and dosimetric characteristics using Gafchromic film of this LEP. Also, we vary the density by varying the amount of absorbed water in ground cork plate. By irradiating the phantom, which simulated a tumor with respiratory motion, we investigate the dose distribution difference between conventional phantom and water-containing phantoms.

\section{Materials and Methods}

\subsection{Preparation Lung Equivalent Phantom}

We used natural cork to develop the LEP. The density of natural cork can vary widely depending primarily on its age (virgin or reproduction) and treatment (natural or boiled) [6]. The factors that affect cork density have been widely discussed. Because the density of cell wall materials is believed to be relatively constant, the global density variations must be related to the cell heights and cell wall thicknesses as well as to the degree of expansion of the cell walls and cell layers [7] [8]. This characteristic is very important for the absorption of plain water. The cell walls can be made from a water-absorptive material, and the cell polygons can be spaced to store the water if special chemicals are added during the cork-manufacturing process. We soaked the cork in plain water for it to uniformly absorb the water. We were careful to ensure a uniform distribution of water in the cork and evaporation of the absorbed plain water from the cork. Since there were individual differences of Corks, the manufactured recipe of wa- 
ter treated cork was varied by its set. Time and temperature of soaking the cork were 6 - 8 hours and $25^{\circ} \mathrm{C}$. For that reason, uniformity of physical density was confirmed every the half hour using computed tomography (CT) numbers for five regions: the centre and four corners of a slab of cork size $20.0 \times 20.0 \times 1.0$ $\mathrm{cm}^{3}$. Also, 30 micrometers of water non-transmission sheets were used to prevent evaporation of the water. The LEP was manufactured five sets. The elemental composition of natural cork and LEP were measured by an elemental analyser (CHN-O mode). In addition, physical density, electron density, electron concentration and effective atomic number were calculated on the basis of the wt.\% of some substitutes [lung (ICRU44) tissue, natural cork and an RMI455 commercial lung phantom (Gammex RMI, Middleton WI)] and our water treated cork. The elemental composition of RMI455 phantom was provided by manufacturer. The mass-attenuation coefficient was calculated on the basis of the wt.\% of each element and data from the NIST XCOM database [11]. The mass stopping power of the mixture was obtained from NIST ESTAR [12].

\subsection{Dosimetry Using Various Density Lung Equivalent Phantoms}

The LEP with different densities regulated the absorb quantity of the water in the cork to mimic a breathing-related density change were irradiated. The density of the water treated cork was set to $0.3 \mathrm{~g} / \mathrm{cm}^{3}$ in the case without density change and to $0.22-0.40 \mathrm{~g} / \mathrm{cm}^{3}$ in the case with breathing-related density change. The presence probability related to the density change was calculated from the equation that Hurkmans et al. [6] had used and allocated to a LEP of different density to comply with the breathing-related density change. In addition, we placed a $4.0 \mathrm{~cm}$ diameter PMMA ball, which simulated a tumor at a depth of $10 \mathrm{~cm}$ from the phantom surface. A Gafchromic film was placed in the centre of the surface and irradiated by X-rays of $6 \mathrm{MV}$ and $10 \mathrm{MV}$ to acquire a dose distribution. The difference between using LEP without density change and one with a breathing-related density change was assessed by considering the dose difference $(D D)$.

\section{Results}

Table 1 shows the physical properties and elemental compositions of the lung (ICRU44) tissue, natural cork, the RMI455 phantom and the LEP. Although the natural cork and RMI455 phantom both contained approximately $55 \mathrm{wt} . \%$ carbon, the lung (ICRU44) tissue contained approximately $10 \mathrm{wt} . \%$ carbon. The LEP had approximately the same composition as that of the lung (ICRU44) tissue, having considerably less carbon compared to natural cork and the commercial phantom. On the other hand, the LEP contained 56.8 wt. $\% \pm 5.3$ wt.\% oxygen as averege result of having make five identical water treated cork sets, and made measurement of each set. The physical properties were also the same as those of the lung (ICRU44) tissue. Figure 1 and Figure 2 show the mass-attenuation coefficient ratio and the mass stopping power, obtained by the explained 
Table 1. The physical properties and elemental compositions.

\begin{tabular}{|c|c|c|c|c|}
\hline & \multicolumn{4}{|c|}{ Lung tissue substitute } \\
\hline & Lung (ICRU 44) & Natural cork & RMI455 & Water treated cork \\
\hline Physical density $\left(\mathrm{g} / \mathrm{cm}^{3}\right)$ & 0.26 & 0.20 & 0.30 & 0.25 \\
\hline$\rho_{\mathrm{e}}($ electrons/g) & $3.32 \times 10^{23}$ & $3.23 \times 10^{23}$ & $3.26 \times 10^{23}$ & $3.28 \times 10^{23}$ \\
\hline$n_{\mathrm{e}}\left(\right.$ electrons $\left./ \mathrm{cm}^{3}\right)$ & $8.62 \times 10^{22}$ & $6.47 \times 10^{22}$ & $9.77 \times 10^{22}$ & $8.21 \times 10^{22}$ \\
\hline Effective atomic number & 7.66 & 6.99 & 7.68 & 7.16 \\
\hline CT number & -950 to -750 & $-783 \pm 13$ & -710 & $-742 \pm 23$ \\
\hline Element & \multicolumn{4}{|c|}{ wt.\% } \\
\hline $\mathrm{H}$ & 10.3 & 7.7 & 15.8 & $16.4 \pm 2.1^{*}$ \\
\hline $\mathrm{C}$ & 10.5 & 56.6 & 54.9 & $26.3 \pm 3.1^{\star}$ \\
\hline $\mathrm{N}$ & 3.1 & 0.4 & 1.8 & $0.1 \pm 0.0^{*}$ \\
\hline $\mathrm{O}$ & 74.9 & 34.5 & 16.8 & $56.8 \pm 5.3^{*}$ \\
\hline $\mathrm{Na}$ & 0.2 & & & \\
\hline $\mathrm{Mg}$ & & & 10.2 & \\
\hline $\mathrm{Al}$ & & & & \\
\hline $\mathrm{Si}$ & & 0.7 & 0.7 & \\
\hline $\mathrm{P}$ & 0.2 & & & \\
\hline$S$ & 0.3 & & & \\
\hline $\mathrm{Cl}$ & 0.3 & & & \\
\hline K & 0.2 & 0.1 & & \\
\hline Ash. & & & & 0.4 \\
\hline
\end{tabular}

Symbol ${ }^{*}$ is indicated the Standard deviation as a result of having manufactured it five times repeatedly.

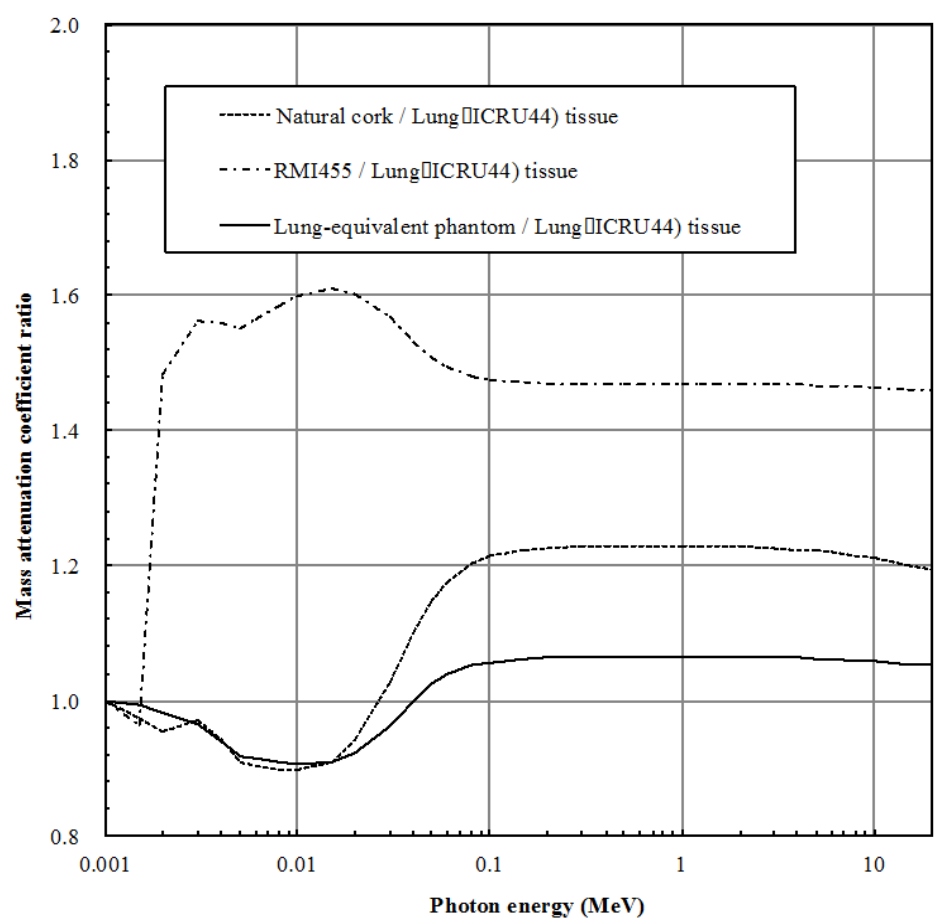

Figure 1. Mass-attenuation coefficients ratio of natural cork, RMI455 phantom and LEP. The value for each substitute is plotted as a ratio to the value for lung (ICRU44) tissue. 


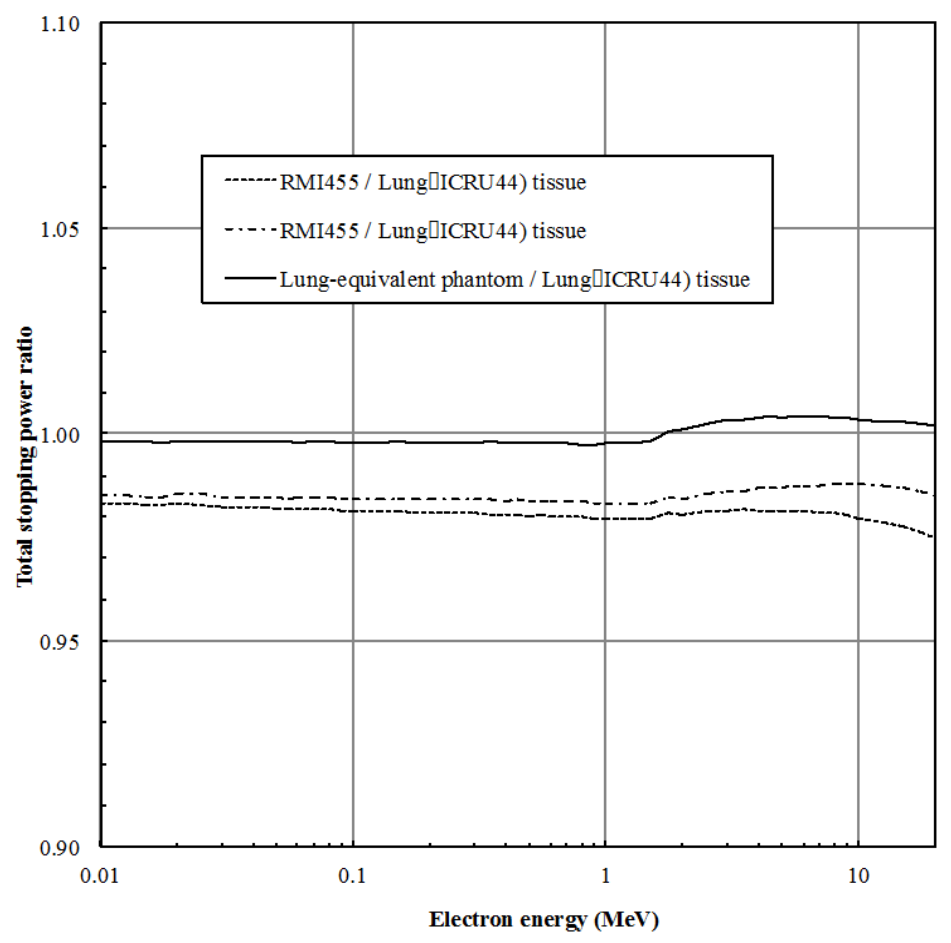

Figure 2. Collision-stopping powers of natural cork, RMI455 phantom and LEP. The value for each substitute is plotted as a ratio to that for the lung (ICRU44) tissue.

changes in the absorbed dose in the radiotherapy energy range. The mass-attenuation coefficient of the RMI455 phantom was approximately 1.6 in the 0.001 - $0.01 \mathrm{MeV}$ energy range and approximately 1.5 in the energy range above 0.1 $\mathrm{MeV}$. In contrast, the mass-attenuation coefficients of natural cork and the LEP were $<1.0$ in the $0.001-0.01 \mathrm{MeV}$ energy range for both substitutes. The mass-attenuation coefficient was constant at approximately 1.2 for natural cork and approximately 1.1 for the LEP at energies above $0.1 \mathrm{MeV}$. The mass stopping power was calculated on the basis of the energy loss of electrons in the radiotherapeutic energy range. The collision-stopping powers of natural cork and the RMI455 phantom were up to $1.8 \%$ and $1.7 \%$ different from that of the lung (ICRU44) tissue, respectively. Figure 3(a) and Figure 3(b) shows a comparison of the dose distributions measured by a Gafchromic film for $6 \mathrm{MV}$ and $10 \mathrm{MV}$, respectively. The dose distributions for both energies showed that the LEP reproduced a breathing-related density change, which was different from without density change. Also, $D D$ was within $5 \%$ different inside $80 \%$ of the geometrical beam. However, in points on and off the central axis, in the build-up and penumbra region, differences of up to $15.6 \%$ were observed in $D D$.

\section{Discussion}

In the present study, we developed a LEP using a cork with absorbed water. We presented the physical properties (elemental composition, physical density, electron density and effective atomic number) with the elemental analyser and 

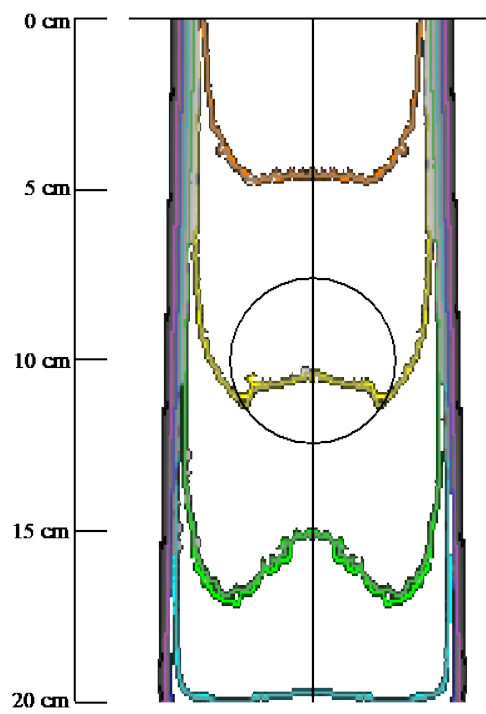

(a)

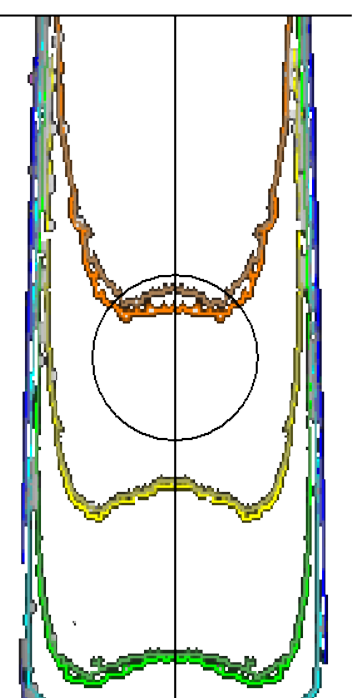

(b)
With a breathing-related density change

$90 \%$

$50 \%$

$-30 \%$

Without density change

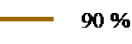

$70 \%$

$50 \%$

$30 \%$

Figure 3. Comparison of the dose distributions measured by a Gafchromic film for $6 \mathrm{MV}$ and $10 \mathrm{MV}$, respectively. Dose distributions in the LEP with breathing-related density compared to that without density change. The isodose curves show the range from $30 \%$ to $90 \%$ at intervals of $20 \%$. Center circle were indicated the location of virtual tumor.

dosimetric characteristics of the LEP with Gafchromic film. Because the LEP absorbed large amounts of plain water, the weight percent of carbon was relatively low. In contrast, the weight percent of oxygen was relatively high. Therefore, the LEP was similar to the lung (ICRU44) tissue in terms of elemental composition and effective atomic number. Dose verification with high accuracy using CT images was performed using our LEP as a human lung-equivalent substitute. In addition, the mass-attenuation coefficient of the RMI455 phantom was considerably different from that of the lung (ICRU44) tissue. This is attributed to the mass-attenuation coefficient of magnesium affecting the whole substitute in the $0.001-0.01 \mathrm{MeV}$ energy range. Natural cork and the RMI455 phantom differed widely from the lung (ICRU44) tissue at energies above 0.1 $\mathrm{MeV}$. LEP can be used as a novel human lung-equivalent substitute in radiotherapeutic dosimetry, because natural cork and RMI455 phantom are different widely from the lung (ICRU44) tissue. The density range of the LEP was set to $0.22-0.44 \mathrm{~g} / \mathrm{cm}^{3}$, i.e. like the lung (ICRU44) tissue. We expended much time and effort for adjustment of the LEP densityon present study. It is an important to provide a means for producing a LEP in a short time period. Respiratory motion is known to affect the physical density of the lung, and thus, the calculated dose in the CT image-based treatment plan [13] [14] [15]. We performed to measure only 1 field irradiation, but radiotherapy with multiple field is provided by much lung cancer patient. Radiotherapy with multiple field with the breathing-related density change is thought to increase the impact to cause to dose distribution. Therefore, treatment planning and radiotherapeutic dosimetry, including the physical density change by respiratory motion, can be determined using LEP of various densities. Because our LEP can be adjusted to different 
densities by the absorption of various amounts of water by the cork, it may be useful in treatment planning and radiotherapeutic dosimetry involving the lung. Although we have not considered the displacement of the tumor due to lung volume change, our water treated cork reproduces the density change, which will allow more accurate dose measurements.

\section{Conclusion}

The present study aimed to develop a LEP by cork with absorbed water so that it uniformly absorbs the water. We presented the physical properties and dosimetric characteristics of this LEP. The physical properties of the LEP indicated that it can be used as a novel human lung-equivalent substitute in treatment planning and radiotherapeutic dosimetry.

\section{References}

[1] Fraass, B., Doppke, K., Hunt, M., Kutcher, G., Starkschall, G., Stern, R. and Van Dyke, J. (1998) American Association of Physicists in Medicine Radiation Therapy Committee Task Group 53: Quality Assurance for Clinical Radiotherapy Treatment Planning. Medical Physics, 25, 1773-1829. https://doi.org/10.1118/1.598373

[2] Ma, C.M., Jiang, S.B., Pawlicki, T., Chen, Y., Li, J.S., Deng, J. and Boyer, A.L. (2003) A Quality Assurance Phantom for IMRT Dose Verification. Physics in Medicine and Biology, 48, 561-572. https://doi.org/10.1088/0031-9155/48/5/301

[3] Ravichandran, R., Binukumar, J.P., Sivakumar, S.S., Krishnamurthy, K. and Davis, C.A. (2008) A Method for Estimation of Accuracy of Dose Delivery with Dynamic Slit Windows in Medical Linear Accelerators. Journal of Medical Physics, 33, 127 129. https://doi.org/10.4103/0971-6203.42768

[4] Chang, K.P., Hung, S.H., Chie, Y.H., Shiau, A.C. and Huang, R.J. (2012) A Comparison of Physical and Dosimetric Properties of Lung Substitute Materials. Journal of Medical Physics, 39, 2013-2020. https://doi.org/10.1118/1.3694097

[5] Tissue Substitutes in Radiation Dosimetry and Measurement. ICRU Report 44 (1989) International Commission on Radiation Units and Measurements, Bethesda.

[6] Hurkmans, C.W., van Lieshout, M., Schuring, D., van Heumen, M.J., Cuijoers, J.P., Widder, J., van der Heide and Senen, S. (2011) Quality Assurance of 4D-CT Scan Techniques in Multicenter Phase III Trial of Surgery versus Stereotactic Radiotherapy (Radiosurgery or Surgery For Operable Early Stage (Stage 1A) Non-SmallCell Lung Cancer [Rosel] Study). International Journal of Radiation Oncology Biology Physics, 80, 918-927. https://doi.org/10.1016/j.ijrobp.2010.08.017

[7] Silva, S.P., Sabino, M.A., Fernandes, E.M., Correlo, V.M., Boesel, L.F. and Reis, R.L. (2000) Cork: Properties, Capabilities and Applications. International Materials Reviews, 50, 345-365.

[8] Cumbre, F., Lopes, F. and Pereira, H. The Effect of Water Boiling on Annual Ring Width and Porosity of Cork. Wood and Fiber Science, 32, 125-133.

[9] Aarup, L.R., Nahum, A.E., Zacharatou, C., Juhler-Nøttrup, T., Knöös, T., Nyström, H., Specht, L., Wieslander, E. and Korreman, S.S. (2009) The Effect of Different Lung Densities on the Accuracy of various Radiotherapy Dose Calculation Methods: Implications for Tumour Coverage. Radiotherapy and Oncology, 91, 405414. https://doi.org/10.1016/j.radonc.2009.01.008

[10] Paelinck, L., Reynaert, N., Thierens, H., De Neve, W. and De Wagter, C. (2005) 
Experimental Verification of Lung dose with Radiochromic Film: Comparison with Monte Carlo Simulations and Commercially Available Treatment Planning Systems. Physics in Medicine and Biology, 50, 2055-2069.

https://doi.org/10.1088/0031-9155/50/9/009

[11] Hubbell, J.H. and Seltzer, S.M. (1995) Tables of X-Ray Mass Attenuation Coefficients $1 \mathrm{keV}$ to $20 \mathrm{MeV}$ for Elements $\mathrm{Z}=1$ to 92 and 48 Additional Substances of Dosimetric Interest. NISTIR-5632, National Institute of Standards and Technology, Geitherburg.

[12] Berger, M.J., Coursey, J.S., Zucker, M.A. and Chang, J. (1992) ESTAR, PSTAR, and ASTAR: Computer Programs for Calculating Stopping-Power and Range Tables for Electrons, Protons, and Helium Ions.

[13] Tissue Inhomogeneity Corrections for Megavoltage Photon Beams, Report No. AAPM-85, AAPM Task Group No. 65, Radiation Therapy Committee (2004).

[14] Fujisaki, T., Kikuchi, K., Saitoh, H., Tohyama, N., Myojoyama, A., Osawa, A., Kuramoto, A., Abe, S., Inada, T., Kawase, T. and Kunieda, E. (2004) Effects of Density Changes in the Chest on Lung Stereotactic Radiotherapy. Radiation Medicine, 22, 233-238.

[15] Hanley, J., Debois, M.M., Mah, D., Mageras, G.S., Raben, A., Rosenzweig, K., Mychalczak, B., Schwartz, L.H., Gloeggler, P.J., Lutz, W. and Ling, C.C. (1999) Deep Inspiration Breath-Hold Technique for Lung Tumors: The Potential Value of Target Immobilization and Reduced Lung Density in Dose Escalation. International Journal of Radiation Oncology Biology Physics, 45, 603-611. https://doi.org/10.1016/S0360-3016(99)00154-6 